\title{
Pay no more than 45 copies: The collection legacy of the Crass Record, Reality Asylum (1979)
}

\author{
Alastair Gordon, De Montfort University
}

\begin{abstract}
This article sets out an auto-ethnographic and theoretical account of the journey of 45 collected author copies of the 1979 Crass Record 'Reality Asylum'. The principle aim in this piece is to document and theoretically situate the production, reception and individual journeys various pressing variations of the record have encountered. The theoretical account is concerned with how and what ways various traditions in semiotics, fan/audience research, critical theory and Derrida's concept of Hauntology can be deployed in explanatory terms to account for the enigmatic, haunted journey of the recorded musical artefact. The article also captures this collection prior to public display, prior to them being resold as the collectable sixth, 'haunted' pressing of the record.
\end{abstract}

\section{Keywords}

Punk

critical theory

auto-ethnography

fandom

hauntology

audience research 


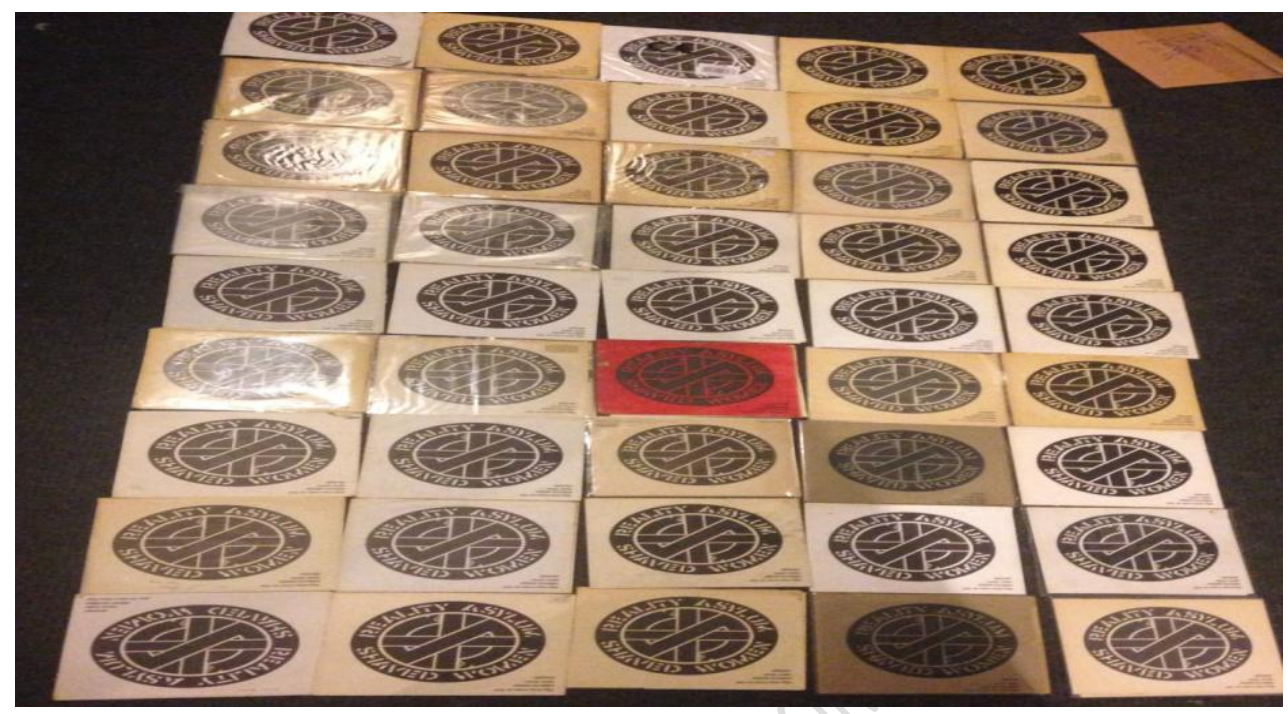

Photo by author, Nottingham, United Kingdom

\section{'I am No Feeble Christ!'}

I presently own 45 vinyl copies of the 1979 Crass Record, Reality Asylum. Yes, this is bizarre, although by the end of this article I trust the patient reader will not judge me too harshly as the personal and academic rationale for doing so unfolds. This record has a troubled and famous history. Indeed, it has been on my radar of fascination since it emerged all those years ago. Its genesis has been clearly documented in detail by the band and other commentators on numerous platforms. I will offer in schematized form below an autoethnographic and broad semiotic analysis of what the record meant to me in my early punk years. Second - and for the newcomer to the record - I will illustrate some of this history, although for a detailed historical account of the band Crass, the curious reader is directed to the bibliography set out below. Third, I will situate the record in terms of its production difficulties before examining the theoretical significance of explaining why this is an 
important record in terms of select examples of historical and cultural theory. Broadly, I note that Reality Asylum is a perfect example of an enigmatic and subversive text with clear contemporary influence on punk record sleeve design and musical output: the reader is encouraged to undertake their own research in this respect. There is both insufficient space and examples to detail within the limited scope of this article. Specifically, my principle interest lies in addressing the detail of the record and equally the historical transmission of the record and its groundbreaking aesthetic. Record collecting and its vicissitudes have been clearly addressed in the cultural studies literature by Thornton (1995), Shuker (2010), Connell (2012) and O'Connor (2008).

Collecting records has been in existence as long as recorded music appeared in the late nineteenth century, and the vinyl format came to prominence in the 1950s. From the testpressing of initial records to the various repressings, live bootlegs and international variations of records in addition to the multiple nuances of internationally franchised versions of records, collectors constrain themselves within the broad corpus of these areas within and across chosen genres. Indeed, with the rise of the 1980s' digital CD and later mp3s and Flacs, the original music embarks upon a strange journey both within the home and across the globe in record collection shelves, attics, cellars, record shops, junk shops, Internet auctions and car boot sales. The list goes on. Some of these discs are invested with love, hate and a range of intermediate emotions, or as a source of trade-value from which to accrue new, more soughtafter recordings. Some versions bought at the time are decorated and inscribed with personalized contributions to the covers. In short, each disc, once free from the artist, embarks upon its own personal and largely untraceable journey. Occasionally, the record is reunited with its original author(s) to be signed and add provenance and individual authenticity to its form. However, it is not my purpose to detect or unveil such musical quests of the object; nor is it within the scholarly remit of the present piece. The second aim of this 
article is to examine how 45 copies of the same record when assembled offer new and fresh meanings to the original art form.

\section{Boredom, technical studies and early punk record collecting}

Being too young in 1978 to fully appreciate the release of the first 12" Crass record, The Feeding of the Five Thousand, and being involved in collecting the standard punk canon of the Sex Pistols, The Clash, UK Subs, the Ruts, etc., introduction to the Crass Record Reality Asylum came as a blindsided shock back in late 1980s. My mate at school was Pat O'Keefe; we had been mates since year two of primary school and by default had managed to remain in the same school form-group. Friday afternoon's lesson was technical studies. It was generally boring and we produced a range of brass enamel pots, spatulas, plant hangers and other consumer-durables in preparation of our eventual working-class factory fate. Breaking the boredom in one of these lessons we got to discussing records. His other mate, Kev Swift, who was a couple of years older than us, had bought a copy of this strange record. It cost 45 pence, had a poster and lots of cool, disturbing artwork attached, and involved strange music and poetry. This sounded much more interesting than your average punk record. I was intrigued. Pat said the Beeston record shop, Music Plus, stocked copies. This shop was run by an elderly couple, close to retirement, and was stocked with low-end musical instruments, amplifiers and hundreds of tatty records. I could not wait for the lesson to finish and passed it with more punk-record small-talk. At twenty to four I was free, cycling over to get my paperround money and blast round the usual posh houses delivering their copies of Nottingham Evening Post. Paper-round over, I cycled down to Music Plus. Flicking through the racks, I could not find anything remotely matching Pat's description of the record. Eventually, I plucked up the courage to ask and the elderly gentlemen went in the back of the shop, returning with the record. 'Looks a bit strange this one, youth', he muttered out in a heavy Nottingham accent. It immediately struck me from the cover that I had seen that symbol 
spray-stencilled around various parts of Beeston. Coughing up the money, I was off, back home to the family turntable.

Let us just say, the 'Asylum' side of the record blew my mind. I thought it was shit! Yet, there was something puzzling about it. I hated religion, although after having all the Church of England religion as the family belief system from an early age, I found it unsettling. This was no Sex Pistols record. It was arty poetry, with wordplay repeated over an unsettling musical soundscape. It was a bit much to take. The second side, 'Shaved Women', was equally bleak. The first thing that crossed my young mind was what the fuck is a shaved woman'? Were they talking about genitals like the magazines in my elder brother's cupboard? Unsettling. The repeated rhythm track of the train-tracks reminded me of the television documentaries on the Holocaust, punctuated by a guitar's single note 'beep'. Eve Libertine's vocals were confident and uncompromising and the closing chorus of 'in all your decadence people die!' equally scared the hell out of me. Overall, the production was bleak replete with haunted, barely audible sub-vocals, it matched the decrepit post-industrial landscape we were growing up in back then.

It was clear this was no usual record. I replayed the 'Asylum' track and the resonance of it hit me hard. The mix of sexual politics, anti-religious sentiment and anti-nuclear commentary had me running for the fusty encyclopaedia in the house to find out more. What did it mean? If anything, this was educational. The stuff taught at school never related to me; this was the start of a second, personal education, which would serve me well to this day. ${ }^{1}$ The art for the record was equally disturbing, and alongside the later Crass output, proved to be the stuff of teenage nightmares for a good few years. It had an impact equal to the music: bleak, unsettling and enigmatic. Initial impressions led me to assume that this was a cut-and-paste job, although I was completely impressed learning years later that these were intricate paintings from Gee Vaucher (1999). Back then I always scrutinized every detail of every 
record I bought, from the matrix-numbers and run-out-groove messages to every aspect of the cover. Up to that point, punk records were composed of vibrant colours, especially the Sex Pistols and UK Subs with their plethora of coloured-vinyl releases. Artwork from these was frequently copied onto bored homework, pencil cases and painted school-rucksack flaps (another story). The cover art had the first example of the now commonplace Crass logo and classic graphic design. The logo was both striking and unsettling. I had spent many hours practising drawing the thing, with the most disappointing egg-shaped results. The cover information and greeting '1945U enola hallo AN.OK? 521984 pay no more than 45p' was yet another suite of enigmas. Comprising of now familiar, yet non-existent back then, SMS text message language with '1945U' and 'AN.OK?', obviously referring to 'anarchy', though obviously not the sort of lawlessness Rotten described in the Pistols 'Anarchy in the UK' track: while the anarchy and Antichrist issues were definitely common ground across the records, they were deployed for entirely different purposes. The 'enola hallo', as I note above, had me dashing for the dictionary, and thus uncovering that this was a reference to 'Enola Gay', the USAF plane, unleashing the atomic bomb devastation on the Japanese city of Hiroshima in August 1945. Most famously, though, was the first example of the Crass pricing-code, designed to undercut and be accessible to those on limited income - perfect for my paper-round money back then. McKay $(1996,1998)$ noted that previous examples of the 'pay no more than' began on the London band, Desperate Bicycles' records, though Crass took this practice to another level throughout their later releases. ${ }^{2}$ Their previous 12 " The Feeding of the Five Thousand released on London label, Small Wonder, contained no such instructions. ${ }^{3}$ In short, the puzzle-framework and musical exploration offered many enigmas for the young and curious punk-minds back then.

Unlike the first-hand screen-printed pressing of the record, discussed below, this record came as an A3 double-sided six-panel poster. To my knowledge this was an unprecedented 
approach, clearly signalling the objective to offer as much a visual as a musical experience. The first panel contained a 1979 diary entry from Eve Libertine offering critique of the Catholic faith, patriarchal religious oppression, the legacy of war and systems of ideological power and religious transmissions of fear. Concluding the final sentence was the now famous

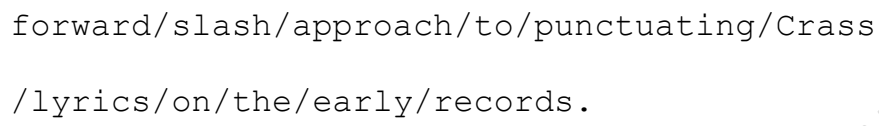

The centre picture is a stark, grainy black-and-white image of the band with Eve Libertine and Andy Palmer playing with Crass in front of their logo. The lyrics to 'Asylum' are reproduced on the third panel as a continuation of the previous diary entry, with the more intense visual image on the fourth panel comprising G's surreal/realist art and Penny Rimbaud's handwritten reproduction of the lyrics for 'Shaved Women'. The latter, to my mind back then, clearly drew on French resistance to World War II Nazi occupation and the subsequent attacks on those women found guilty of collaboration by sleeping with, or associating with, fascists. My research back in 1980 revealed that those found guilty of this had their hair publicly shorn and were subject to abject beatings. As for the babies screaming, my take on this related to the extermination of children in the Holocaust gas-chambers as per the train-track loop under the music and the looped sub-vocal 'screaming babies', evident under the entire song. Other symbols of modernist housing punctuate the background while a Churchillian, heavy-framed spectacled male, sternly puffing on a cigar, dominates the foreground. The Catholic nuns saluting an SS officer and priests with Nazi salutes indicated the complicity of the Sea of Rome with the outrages of the Holocaust, 'Decadence' here referring to the enrichment of the latter through Nazi complicity. 
The main poster for this record was one of the single most disturbing images of my teenage years. Superimposed over the rendering of what could be understood as the grounds of a Nazi death-camp site, the painting depicting dead Jews, Catholic Church imagery, Jesus guarded by a casually dressed male in T-shirt - certainly not in keeping with the World War II theme, although clearly denoting the continuation of military aggression and protection of organized religion. Juxtaposed clockwise is the slowly collapsing church, denoting secularity yet oddly still struggling to maintain prominence in an increasingly deadly culture under the Cold War nuclear threat and echoes of Hiroshima. However, the most eerie, disturbing centrepiece of the painting is the adolescent ghost-girl replete with stigmata and shroud. Her pasty, death-like complexion, framed by the symbol of death and mourning in Western European culture, the lily, foregrounds the image, concluding the visual narrative. Collectively, the image offers another set of enigmas regarding exactly what the collective ideological meaning is, although I assume this is not the point. Instead, the general lyrical/musical themes of the record - as would become the central practice on Crass releases - was critically juxtaposed offering a powerful ideological critique of both recorded tracks.

Finally the back cover, I remember studying this in some detail back in 1981. Not only were the unsettling visual images and general enigmatic approach tied together with the art and graphic design, the credits on the back cover raised more questions than the record offered solutions. Gone were the traditional four or five member rock and roll standard musical recipe and additional tape/backing 'voice' credits, etc., inserted instead. In punk tradition, a series of now famous and enigmatic names are listed in a collective roll call: 'Eve Libertine/Gem Stone/N.A/Palmer/Pete Wright/Penny Rimbaud/Phil Free', although more enigmas occur at the end with the inclusion/exclusion tactic of 'Steve Ignorant' and 'Joy De Vivre (virginia creeper)' credited as non-appearance. Standard production credits follow with a thanks list of those bands and individuals to feature in the genesis of the band over the 
following six years. Equally, the much-discussed Crass Records catalogue number makes its first appearance trading on an Orwellian countdown to 1984. The final enigma for the reader is evidenced here. Back in 1981, to my mind a countdown to what exactly? The end of the world, nuclear destruction? Death? The messages offered the notion of 'anarchy and peace', certainly not the 'chaos and destroy' of the standard punk-fare back then: what was this? These were questions only further investigation of both their previous record and future material and live performances would reveal.

Judging by the sheer number of enigmas on this record, I am not surprised at the number of letters the band received at their Dial House base. Indeed, if the number of puzzles indicated above is anything to go by, then the curiosity of not only myself but the interest of a whole generational swathe of young UK punks had been brought to life through a 45-pence introduction to the mysterious, black-and-white world of Crass.

I used to play the record at low-volume, worried that my parents would overhear it. Things in my family were like that and my father really would not have appreciated the sentiments on that record. That said, the record was soon surpassed by Crass's next release, 1979s landmark, Stations of The Crass, although that record is not the subject of the present discussion. The Reality Asylum record still had clear potential to offend the conservative aspects of society back then. In the summer of 1983, this became evident when my friends and I were allowed to DJ some punk records at our local youth club open-air disco/barbeque, held at a Church and run by ageing Methodist Christians; let us just say our presence there each Thursday was a constant thorn in their righteous flesh. They hated having their beliefs challenged and debated on a weekly basis. After the standard pop-tunes had done the rounds on the decks we jumped up; the courtyard was full with youth waiting for the next record. For a while the opening sample of the children on the record blended in with the general chit- 
chat, and the gradual buzz of the background synthesizer gradually got louder aided by our raising the volume...then ...

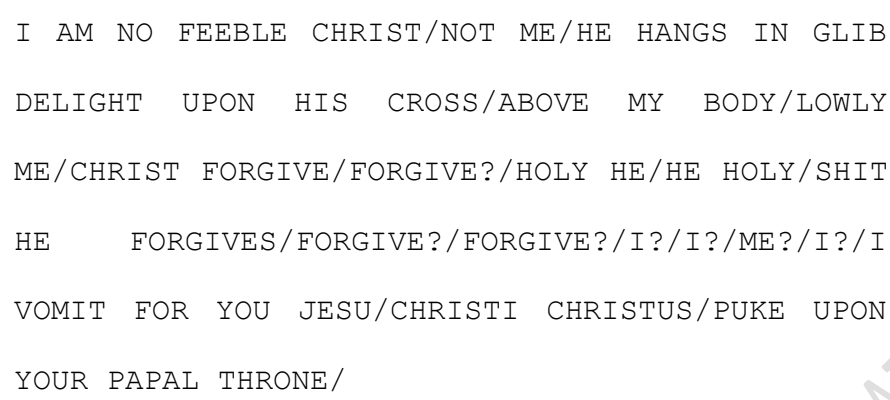

The end of the quote is roughly where one of the Christian youth-leaders dashed over with a stern face and scratched the record off the deck with a very audible riiiip! Silence. Tim, who was with me on the decks, said 'sorry mate' to the youth leader, 'wrong side', but he knew we were messing with him. The eyes of disgust aimed from the previously dancing and jovial crowd at us was a right buzz, especially the smirks on the faces of our punk mates, who were in on the joke. Tim quickly put another record on the turntable. 'Any more disrespectful funny business and you and your mates can get out'. Too late, the next record's - the Anti Nowhere League's 'So What' - opening lyric blasted into the audience silence - 'So fuuuucking whatttt! - before ripping into the gnarly guitar riff, which was equally scratched off the deck. We were politely told in no uncertain terms to leave and not return. So much for Christian understanding! Mission successful. The statements on that first Crass 7" reinforced our anti-Christian mindset and were successfully deployed at the advocates of organised religion.

\section{Theoretical interludes}

The objects and expressions of music are long associated with the traditions of critique, aesthetics and rebellion. Key in the present interlude is the notion of art compelling, not 
demanding, the reader accepts the critical meanings contained in the art form. This is the well-trodden discussion famously offered by Adorno and Horkheimer ([1944] 1995) and Benjamin ([1934] 1995).

For Adorno, the purpose of art was to 'compel and not demand', to shake the reader out of an uncritical slumber. With Horkheimer, Adorno discussed in the landmark Dialectic of Enlightenment ([1944] 1995) the uncritical aesthetics of mid-twentieth-century western capitalism of a subjugated proletariat, driven by physical and bourgeois control of survival needs, and a punishing aesthetic of distraction. Horrified, arriving as German Jewish exiles in metropolitan New York in the early 1940s, the theorists were struck with this uncritical industrial aesthetic of unbridled capitalism and the perceived horrors of modern Jazz music, film, advertising and mass-produced art. Their key discussions on why the revolution Marx so faithfully predicted had not occurred in western culture in a society with the technological capacity to create a utopian existence had instead reverted to mechanized forms of barbarism and oppression in the service of elite dominant groups. The chapter 'The culture industry: Enlightenment as mass deception' offered a critical and somewhat pompous solution to this practical problem. Music was discussed as a 'pseudo-individualized', normative force and cultural products from advertising, genre, narrative, film, architecture and all forms of popular entertainment painted as dull, uncritical, 'standardized' forms.

The key to a radical and rebellious subjectivity capable of challenging the system, for the authors, was the nurturing of a mass negation and realization of the true state of capitalist exploitation, religious distraction and the dull-compulsion of proletarian labour. Any rebellion arising out of such conditions was considered by the authors 'always already' part of the culture industry and assimilated back into the latter, rendered safe and ultimately uncritical: a shrivelled, fettered and piecemeal shadow of what they deemed 'true' revolutionary resistance potential of radical art forms. Undoubtedly, and aside from the elitist 
and bourgeois notions of art and music - for example, Leonardo DaVinci and Berg compositions as the 'true' source of mimetic critique - there was a definite argument for the potential of enigmas in art to compel audiences to criticize (negate) the systems of ideological control and constraint. Admittedly, this is overdone in this book. Their arguments overlooked and misunderstood those critical spaces in culture where radical potential can be staged. This critique was vehemently offered by Walter Benjamin in a work preceding the 'Culture industry' thesis, namely The Work of Art in the Age of Mechanical Reproduction, in the posthumously published Illuminations ([1934] 1995), in which he outlined the potential in the mechanical reproduction to circulate and challenge and subvert what he deemed forms of 'auratic' art. In the same sense as Adorno, Benjamin was aware of the radical potential of high art, yet equally predicted the benefits of its mechanical circulation in spaces of mass culture.

Later critiques of the culture industry took place within the cultural and ethnographic study of audiences (Morley 1978, 1986). Fiske (1990a, 1990b, 1992) noted the potential of how audiences semiotically reinterpret and often radically renegotiate the signs of popular culture in the overdetermined space of Adorno and Horkheimer's culture industry output. Often, heralded and misguidedly hailed in numerous cultural and audience research as champions of the 'effects model' of audiences, the ideological mind-control machine of the cultural dope, the culture industry thesis contained a far more sophisticated critique of mass aesthetics than did those detailed introductory accounts of the essay. This critical notion was certainly retained by Stuart Hall in his $(1973,1980)$ pioneering work on 'encoding and decoding of television forms'. The structuralist argument drew on Barthesian semiotics, Saussureian linguistics, Gramscian notions of hegemony and ideology critique. Key messages and cultural practices are drawn together in the cultural and technological sphere (systems of meaning) and 'decoded' in turn by audiences across a set of reader/audience positions: 
preferred, negotiated and oppositional. While clearly clumsy and slightly restrictive, Hall identified an oppositional within culture: that meanings supporting and espousing dominant views can be resisted and subverted by audiences. Abercrombie and Longhurst (1998) noted this and similar work as the 'Incorporation/Resistance Paradigm' of audience research. Rather than the causal notion of immediate effect/affect, audiences were credited with more critical and rational understandings of audience engagement with media texts: they resist hegemonic dominant textual meaning. This paradigm clearly echoed Adorno and Horkheimer's recognition of audience power in this respect as they famously noted in their concluding discussion of advertising, 'The triumph of advertising in the culture industry is that consumers feel compelled to buy and use its products even though they see through them' ([1944] 1995: 167).

This would be only half the story; audience research proceeding into the 1990s signalled a much more active and creative audience than did Incorporation/Resistance models of research - centrally, the notion that spaces exist for audiences and increasingly fans of culture to create and subvert original authorial intent. This work clearly took influence from Debord's (1967) Society of Spectacle, and Barthes timely work of literary theory, S/Z ([1970] 1974), the principle approach being that the 'death of the author' is 'the birth of the reader' (Barthes [1967] 1977:148). Audiences were now free to creatively 'write' their own meaning and perform/slash/subvert/hack/rewrite/jam and generally reconstruct the original cultural arguments and forms. Clearly, such notions were bound up with the relativist intellectual fashion of postmodernism and post-structuralist theory, which overtook Marxist-informed cultural studies from 1968 onwards. However, while such relativism is implicit in these accounts of audience/fan empowerment, the notion of reclaiming and redeploying, meaning from hallowed authorial lands, offers and signals radical and subversive audience sensibilities at play. 
Henry Jenkins' (1992) insightful revision and deployment of Michael De Certeau's The Practice of Everyday Life (1984) dealt with how fans actively 'poach' from the lands of the esteemed author to recreate and reappropriate texts for their own use. Not only does this argument allow discussion and exploration of how and in what ways traditional art forms are reappropriated and influentially redeployed, it equally demonstrates tensions within the class of the producer of art and the nomadic fan as reproducer and subversive rewriter of the original form. Cultural examples of this practice are legion in western culture, from fan/slash fiction, mash-up culture, Internet memes, tribute bands, forgers, art terrorists, Dadaism, etc. Obviously, tensions arise in such reappropriation, yet equally it allows audiences and fans of established cultural practices to explore enigmas and questions raised in original forms of art and cultural production. Jenkins' argument has clear merit in the present discussion in accounting for the way audiences and fans reappropriate previous art for new and often subversive purposes.

Taken together thus far, the notion of enigma and compelling questions contained within art and subversive reinterpretation of the latter are now open to exploration. This issue lies at the very heart of the Abercrombie and Longhurst notion of 'Spectacle' (art form as perceived) and 'Performance' (reconfigured cultural text as fan reinterpretation as performance). Finally, the kernel of the argument can be stated. The Crass 'text', the Reality Asylum record, can now be examined. As I argue below, this text contained a number of critical enigmas raising questions not only regarding the intrinsic musicological and aesthetic enigmas contained within it but also the cultural journey of the text beyond the authors' intention. This means exploring what occurs to it beyond its release and how and in what ways it functions after it has been sold. Semiotic investigation of the ideological and mythological value of the text only takes the present investigation so far (Barthes 1957). Cursory investigation within the semiotic remit was readily offered above in an auto-ethnographic, historical account of 
exactly what the personal enigmas Reality Asylum meant to the author and how it functioned as both an individual and socially subversive text. Such discussion underlines the central notion that Reality Asylum is an internally and contextually coherent set of ideological enigmas in both musical and artistic/aesthetic terms. What are the meanings presented on the record? How do they function? What are their values culturally when the text escapes onto its own cultural journey and new relationships develop between it and the new owner? Such questions are presently left open to the new reader: that is down to you.

The last question is investigated in the final sections of this article. Following Jenkins (1992), I have already spoken of the fan as a nomad, although what of the text? I examine its role as a nomadic commodity, spun on various types of turntables across the world, and its art displayed on anything from bedroom walls to being later framed in family homes and appreciated as a badge of punk membership and as an art form, or alternatively languishing in used record-bins, attics, record collection shelves and second-hand stores. Copies collect dust at the back of cupboards or migrate digitally onto second-hand websites, Internet auction and resale sites or have their legacy discussed and poured over in nostalgic conversations on past punk experiences or new ones with young and old newcomers to the record: this record has a life beyond the original use as a record with a message. The intrinsic, ideological and authorial meaning accompanies its artefact on this journey but is subject to unlimited creative interpretations. As will become clear, this record has spread across the world on thousands of individual journeys with its reception a matter for the owner. Hence, we return to the Hall notion of 'decoding' and the question as to whether the intended meaning of the record is accepted, negotiated, rejected or just plain ignored.

The postmodern turn is of further value to the present discussion in that linear narratives of the commodity form are unhelpful in exploring the journey of the commodity. Giles Deleuze (1980) famously noted that cultural forms have an intrinsically unstable quality to them. To 
paraphrase the Deleuzian argument, the common sense, traditional account of the journey of the commodity, in the present case, The Reality Asylum record, can be read as 'Arbolic': that is a linear, tree-like structure detailing each potential pathway. However, such accounts have little to say regarding the unpredictability and unexpected reappearances of the 'Rhizome', a 'non-linear, anarchic and nomadic' cultural form (Guedes-Bailey et al. 2008: 25). Each point can connect to another regardless of similarities or differences. Rhizomatic forms allow the 'textual poaching' and uncertain transmission of Reality Asylum to be rendered explicit. The unpredictable, precarious status of such journeys ultimately mean that such records can be relatively dormant for years and decades before reappearing in discussion or reinterpretation of the original, intended meaning.

Not only can this refer to the record per se, it can equally refer to the aesthetics, graphic design, art's ideological and discursive meanings and associate producer influences contained in all of the previous forms. Jacques Derrida in his famous Spectres of Marx (1994) discussed how the ghost of Marx's philosophical oeuvres, rhetorical motifs, radical ideas, writings and legacies inflect present discussion of all resistant cultural discourses of class. This argument acts in spite of neo-liberal proclamations that global free-market capitalism is the de facto way of organizing human activity on the planet. Here, Derrida is not explicitly discussing paranormal events, rather its role as a discursive metaphor: the suitability for exploring and illuminating phenomena other than the putative return of the dead (1994: 2). He clarifies how the present always already contains the past,

To believe or not believe in ghosts no longer involves a determination about the empirical (im) possibility of the supernatural, but indicates contrasting validated attitudes - a welcoming seen as ethical and enabling, and a rejection 
considered unethical and dispossessing - towards the uncertainty, heterogeneity, multiplicity, and indeterminacy that characterise language and Being because of their inevitable entanglement with alterity and difference. (Derrida 1994: 9)

In their new spectral guise, certain features of ghosts and haunting - such as their liminal position between visibility and invisibility, life and death, materiality and immateriality, and their association with powerful affects like fear and obsession quickly came to be employed across the humanities and social sciences to theorise a variety of social, ethical and political questions. (Derrida 1994: 2)

And as Pilar-Blanco and Peeren clarify,

For Derrida hauntology reshapes history by disrupting its conventional structure of chronology 'haunting is historical, to be sure, but it is not dated, it is never docilely given a date in the chain of presents, day after day, according to the instituted order of the calendar'. (Derrida 1994: 4 in Pilar Blanco and Peeren 2013: 13)

Derrida's notion of hauntology - a play on the philosophical term 'ontology' - is of merit in this discussion. Hauntology addresses how and in what ways a range of significant artefacts of the past always already aesthetically and linguistically haunt present, often intuitive 
interpretations and contemporary cultural discussion. As Del Pilar Blanco and Peeren note, 'Derrida, then, far from being a ghostbuster like Freud and Adorno, and Abraham and Torok, uses the figure of the ghost (without ever fully apprehending) that which haunts like a ghost and, by way of this haunting, demands justice, or at least a response' (2013: 9).

The Crass aesthetic pioneered on the cover of Reality Asylum is a much copied image from virtually the release of the record to the present day: not only this fact but equally the way such punk aesthetics return to haunt genres outside of the frequently scrutinized punk canon. Maria Del Pilar Blanco and Esther Peeren (2013) have developed the notion of hauntology into spectralities and how 'spectres' of the past can appear - following Avery Gordon's notion of haunted sociological imaginations -

The ghost, even when turned into a conceptual metaphor, remains a figure of unruliness pointing to the tangibly ambiguous. (2008: 9)

The ghost can question existing forms of knowledge

Ghosts arrive from the past seeking to establish an ethical dialogue with the present. (2008: 12)

Here, notions of the Holocaust, patriarchy, class relations, collaborators and 'shaved women' all return as spectres of historical residues of cultural 'trauma' and memory to 'haunt' the visual and artistic landscapes of Reality Asylum through an enigmatic and haunted presence. As Pilar del Blanco and Peeren note, ghosts are part of a symptomatology of trauma, as they become both objects of and metaphors for a wounded historical experience (2013: 12). 
In an ironic twist, the influences of past rebellious art from the anti-fascist montage of John Heartfield, the Dadaists, Andy Warhol pop-art and the surrealist canon were bricolage for new, rebellious forms of representation on Reality Asylum (Hebdige 1979). Equally, the musical tradition of rock and roll is aurally haunted and subverted via alternative approaches to recording and production through extra signification of children's playground sounds, vocal treatments/reverb, train-tracks and mechanistic rhythm, transgressing the increasingly conservative approaches to music production of the late 1970s in spite of the punk intervention. The haunted enigmas of Reality Asylum are both implicit and explicit on the record and the legacy of the latter has haunted other art forms on a number of platforms of western underground and mainstream cultural production.

\section{The collection: Record history; pressing variations; personalized versions}

Reality Asylum was created by founder Crass member Jeremy Ratter aka Penny Rimbaud as a written text entitled Christ's Reality Asylum and Les Pommes Printemps early 1977 at Dial house, Essex. It originally took form as a 30-page, typed and risographed monograph on the corruption, entwinement and gender oppressive notion of religion and the state. The main cover image gave birth to the now famous Crass Symbol. Rimbaud recalls,

On the frontispiece of the book I included a symbol designed by

Dave King, a friend since our days at art school together, and an ex-communard. The symbol represented the various forms of oppression that I'd discussed in the book: family, church and state. Heraldic in quality, part national flag, part cross, part swastika, the circular design broke on its edges onto two serpents' heads, suggesting the power it represented was about 
to consume itself. It was an extraordinarily powerful piece of work which, having later been adopted by Crass, became synonymous with the anarcho-punk movement that we spawned. (2014: 84)

Already, pre-existing haunted discourses of resistance of power corrupted and enigmas were embroiled into this now iconic symbol. Its journey had begun in earnest. Rimbaud recalled how copies of the latter were selling surprisingly fast across London. With the formation of Crass around this time, the symbol found way onto the Small Wonder pressings of 1978s The Feeding of the Five Thousand 12". This time, Rimbaud's poetry enunciated on the track by Eve Libertine ran into immediate problems at an Irish record-pressing plant. The majority Catholic staff took offence at the anti-religious sentiment on the record, refusing to handle it. As a result, the record was pressed with silence replacing the track entitled 'The Sound of Free Speech'. A tape of the track was sent by the band to those requesting one: the sleevenotes on the Feeding 12" made the bands feelings on this clear:

THE SOUND OF FREE SPEECH. once again the violent majority assert their bigoted reality through the silencing of others. ASYLUM, an antichrist/feminist statement read by Eve Libertine, has been erased because of the refusal by any company to press the record if it was left intact. We apologise. For a copy of the words, or a cassette copy of the censored track, send a stamped addressed envelope, plus cassette if required, to CRASS, c/o Small Wonder.(emphasis in original). 
Reflecting on the personal feelings the Rimbaud-penned Asylum track meant for them, Eve Libertine in an interview with George Berger in 2006 remembered her feelings regarding the track:

I did question it. But I think it was relevant, from the feminist angle. Christ was celibate, Mary was celibate, the whole thing of women's sexuality... it was quite hard for me because I was brought up thinking Christian. So I certainly had to question it but I saw it from a different angle through the 'Asylum' lyrics. So I was prepared to do it. [...] I do see it as an attack on religion, even though it's seemingly attacking Christ. It's attacking what religion took from this. (2006: 135)

The censorship drove Crass to form their own label, Crass Records, giving rise to the first copies of Reality Asylum. The record displayed the Crass symbol as its centrepiece surrounded by the stencilled title circle marking one of the defining and residual design approaches of punk (King 2013; Bestley and Ogg 2012; Baker and Savage 2013). Rimbaud remarked on exactly how the record label was formed in true DiY punk fashion:

Benefiting from our own enterprise in the form of royalties from the first album, and boosted by an inheritance left to Andy [Crass guitarist] by his grandmother, we had finally been able to induce a pressing company to manufacture 'Reality Asylum'. 
Not content with the original recording, we had re-recorded it and then, rather than having to search around for a printer, we had printed the first five thousand covers ourselves. (2014: 102)

The first pressing of Reality Asylum is a beautiful example of the results of hand-screen printing record covers. Printed on heavy card, this version does not contain the later poster versions of the record, instead adopting a book narrative approach with the insert and record paper record housing stapled to the cover. The reader is greeted with the G-Sus poster image, previously discussed, followed by the lyrics printed in bright red - capital letter - ink, which remains striking after approximately 40 years. In the middle is the vinyl record, replete with white-stencil track names printed on black background, followed by the Libertine diary entry - again reproduced in red. The Nazi-saluting clergy occupies the last page. The back cover of the record is virtually identical to later pressings, although with a slightly smaller font and handwritten Crass name logo. The notable difference between the later pressings and the present version is the lack of the Andy Palmer/Eve Libertine Image.

With the record now firmly in the public domain of the UK record-buying public, the reaction from authorities came quickly with a visit from the Scotland-Yard Vice Squad. Rimbaud noted,

Following an interview that left neither them nor ourselves any the wiser, and clearly taken aback at our mild manners, they left us with the threat of prosecution for 'criminal blasphemy'.

'God knows why' muttered one of the detectives, leaving us in little doubt as to whose side he was on. Eventually we received a 
note from the Director of Public Prosecutions informing us that the case had been dropped, but warning us that further indiscretions would be viewed most unfavourably.

However, it very quickly became clear that the decision not to prosecute had been discretionary. Within days of receiving our reprieve, we learnt that record dealers throughout the country were being warned that stocking our material could lead to prosecution, a complete lie, but one that invariably had the desired effect. (2014: 103)

The 'standard' Reality Asylum version was later distributed in 1979 with a poster-sleeve printed on paper resembling flimsy newsprint. This was the first of four further pressing variations of the record with later versions featuring differences in paper quality. Aside from the first screened cover version, a later Japanese pressing licensed by London label, Rough Trade, are examples of the highly collectable versions of the record. The (1981) Japanese pressing contained additional information with a 'pay no more than' 700 Yen and translated information added to the front cover. The cover art and sleeve-size were slightly smaller, yet retained the - slightly thicker - newspaper of the second-press. The lyric information and other details relevant to the Japanese market are translated on the inner poster-sleeve. The most notable difference to the original sleeve are the commercialist adverts for other Rough Trade releases, such as Blue Orchids, Mark Beer, Scritti Politi, The Pop Group's second record, Missing Scientists, Robert Wyatt and TV Personalities. There is an additional printed paper cover displaying a large Rough Trade logo and manufacturing details of the Japan Record Company and the distributor, Tokuma Musical Industries. However, the stark difference is the redesigned back cover, containing the diary entry and 'Asylum' lyrics in 
much reduced text size, and additional adverts for releases from Cabaret Voltaire, The Pop Group, Delta Five and Swell Maps. The 'pay no more than 45p for this record' remains in place regardless of the new south Asian location the record found itself in. ${ }^{4}$ The final destination for the tracks on the Reality Asylum record released was the Crass singles compilation, Best Before (1984b), with the added mock police interview segment added to the beginning of 'Asylum'. The various pressings sold well and provided the backdrop to the art form version discussed below. However, there were unfortunate consequences in store for this particular record, as Penny articulates once again:

From the outset we had decided to market our records as cheaply as possible. Living expenses at the house were so low, so why not pass that benefit onto the punter? However, having miscalculated the percentage taken by the retailers, Reality Asylum had gone out at forty five pence. Every record we sold lost us half a pence, and as inflation grew so did our losses. (2014: 105-06)

Such tales articulated above offer the standard and very broad narrative of the band's view on the production of Reality Asylum. As noted in the previous section, that is only half of the story. It is to the poached narratives to which I now turn.

\section{What a Crass textual poacher!}

Since mid-1978 to the present I have collected thousands of punk records. For many similar collectors Reality Asylum would just be one record among many, or would possibly be rendered obsolete and sent on another journey, or even discarded to the eternal secrets of the 
landfill dump. On my record collecting travels I have always taken pity on seeing these Crass records languishing in the racks of second-hand record stores, car boot-sales, tat shops and in the job-lot collections I have occasionally had the good fortune to buy. The Crass logo is now permanently who I am, having had the logo tattooed on my arm back in 1990. I have picked versions of the original first-pressings up for small pence in Cornish record stores to eventually hunting down a mint condition Japanese version back in 2009. Gradually, the record racks began to swell with various rescued Crass records, copies of Bloody Revolutions, Nagasaki Nightmare, Sheep Farming in the Falklands, etc. That said, the number of copies of Reality Asylum began to significantly outnumber these other records. Something enigmatic was different about the individual ways the Reality Asylum sleeve aged. The newspaper print sleeve suffered entropy at a significant rate, yellowing and individualizing each copy in a plethora of competing hues, displaying various tears and signs of past use. In some cases, corners or entire sections were missing and the owner names were scribed in pen at various points of their individual journeys. Other examples of personalization were a copy with the cover neatly coloured in red marker: very striking. The record tops were often tattered and torn from years of anxious fingers flicking through collections and record racks, each touch leaving its individual, minute sweaty fingered residue to the total look of the cover. The early screen-print versions (I have two copies) have aged into a mustard colour with the inner pages retaining the original white paper. Other interesting examples were a bar-coded price sticker for a hi-visibility jacket attached to a PVC sleeve in addition to a whole host of varying price stickers and associate residue all adding individual touches to the records.

For those purchased from Internet auction sites, I received the occasional note from the seller complementing me on my choice purchase. The general price paid for the records stemmed from the $45 \mathrm{p}$ on my original record from 1979 to upwards of $£ 40$ for the Japan press. On average, the cost of each record was around $£ 8$ excluding postage. By around 2010, 
the number of copies had swelled to thirteen. Used record sites and online auction sites now had a foothold in the collectors market, opening up the possibility of owning numerous copies from across the western world. Back then, I was teaching undergraduate courses on audiences and fandom, often using my rabid record collector skills to illustrate points in lectures and seminars to often bemused young students.

Like a lot of collectors the event of smartphone technology offered opportunities to post pictures of important records to social networking sites for 'like' click-bait. I posted a Facebook picture back in 2012 of the copies of Reality Asylum and they looked great together. Just like Warhol's pop art reproductions of cans of Campbell's soup disrupted the original meaning, the same 'reproduction aesthetic' became evident in my ad hoc collection. The record was instantly transposed into art. So, over the next three years up to May 2015, 45 copies of the record from mint condition to absolute scrap were purchased: the only parameter was that the record had to be complete with vinyl, inner cover and poster. The number of copies purposely mimicked the cover price. Meeting Penny Rimbaud at two separate Punk Scholars Network (PSN) events between 2013-2014 allowed the opportunity to have him write messages on the cover. I asked him not to sign but instead write the first message that came in his head. The original artefact returns to the instigator and the results proved to be very interesting.

From the social-network pictures of competing stages of the collection I was approached in 2013 by Rose Walsh, a fellow PSN member, to exhibit the records at an event detailing foolish forms of artwork. I immediately agreed as this was a great opportunity to explore further the rather odd collection I had amassed, and the completion of the 45 records went into overdrive: an opportunity to collectively gather the records together in the public sphere as an act of subversion. The records were furiously purchased and arrived weekly from Greece, Russia and a lot from the United Kingdom, Germany, the Netherlands, Japan and the 
United States among others. All arriving copies had a pressing number and condition assigned on the original mailer. The records were displayed in their entirety at 'The Fool' weeklong public exhibition curated by Rose Walsh in Leicester, November 2015 alongside other 'foolish' and rebellious art forms, such as a twenty-foot plaster-of-Paris statue of the Dave King Crass logo.

The Fool 01-03: Exhibition of Crass record sleeves by Alastair Gordon, Leicester, November 2015. Photograph by Sarah Gordon, Nottingham, United Kingdom.

Within a cultural context, serendipity always occurs when engaged in such projects. In June 2013, Rutherford Chang, a Californian record collector, began collecting copies of the Beatles White Album, amassing by 2013693 copies of the record, which were subsequently displayed at a New York SoHo gallery. Chang has a New York record store with the purpose of expanding the collection. He noted in 2013 that each copy has a story to tell, and files the records in line with their individual sleeve numbers. As an example of Henry Jenkins' (1992) notion of textual poaching, this collection clearly presents how each record has its own tale replete with individual owner art contributions to the plain sleeve art. This was an activity unbeknown to me at the time, yet the parallels between the two projects are obvious (Chang 2013)

The Fool 01-03: Exhibition of Crass record sleeves by Alastair Gordon, Leicester, November 2015. Formatted: Justified Photograph by Sarah Gordon, Leicester, United Kingdom.

The Fool 01-03: Exhibition of Crass record sleeves by Alastair Gordon, Leicester, November 2015.

Photograph by Sarah Gordon, Nottingham, United Kingdom. 
That such passing similarities exist aside from the 'textual poaching' implications are neither here nor there for the present project. The sole aim of collecting the Reality Asylum records together as a public art form was to gather those records together for a short time to collectively - as per Derrida - 'haunt' new cultural and digital arenas before allowing them to re-enter the private market once again in 2017. Each record to be resold will be individually marked 'Spectre-Press' with a red-numbered stamp to mark their passing through the collection and adding another individualized edition to the pressing editions. ${ }^{5}$ The copies become new spectres of future record collections in their own right. As I noted above, the Deleuzian notion of the rhizome is of particular interest here. The collection has been enhanced by both 'Arbolic' forms of collection - the physical act of entering a record store across four odd-decades and the hyper-digital connections of online auction and record trading sites, resulting in the 'Rhizomatic' gathering of the collection in a fresh, subversive arena: the resale post 2017 will launch these records back onto the market through both Arbolic and Rhizomatic pathways.

The Fool 04 Poster: Poster for The Fool exhibition, Leicester, November 2015. Design by Rose Walsh, Bristol, United Kingdom.

\section{Conclusions and future plans and other ridiculous ideas}

This article has been a journey through theoretical, ethnographic and artistic landscapes, all serving their specific purpose of charting the journeys of the record Reality Asylum, the core notions of personal experiences, theoretical comparison and reflective notions of the records being reunited and publicly displayed before being sent once more on their way to new homes in the record collections and record trading sites of the digital world. It is too early to report on the experiences and reactions to the gallery exhibition in their new, temporary home next to other 'foolish' examples of subversive art. These records will both outlive myself as a 
human being and will ultimately form the subject matter of future generations of punk scholars. That said, the aim of this work has been to unpack the enigmatic qualities of the 40odd-year journey of Reality Asylum both as a personal, cultural experience and as a textually poached new, subversive art form.

There are plans afoot, driven out of sheer curiosity, to both photograph the records posters as a collective display and to simultaneously play and record all 45 copies of the collection. This ultimately will be the concluding chapter of this self-funded piece of punk research before the artefacts are distributed back into the punk record world.

Alastair 'Gords' Gordon (December, 2015)

\section{Acknowledgement}

Thanks to Rose for the support and belief in the project.

\section{References}

Abercrombie, N. and Longhurst, B. (1998), Audiences: A Sociological Theory of Performance and Imagination, London: Sage.

Adorno, T. and Horkheimer, M. ([1944] 1995), 'The Culture Industry: Enlightenment as Mass Deception', Dialectic of Enlightenment, London: Verso, pp. 120-167.

Alberto Y Lost Trios Paranoias (1979), Heads Down No Nonsense Mindless Boogie, United Kingdom: Logo Records. 
Baker, S. and Savage, J. (eds) (2013), Punk 45: The Singles Cover Art of Punk 1976-1980, London: Soul Jazz Records.

Barthes, R. (1957), Mythologies, London: Methuen.

(1964), Elements of Semiology, London: Cape.

__ (1974), S/Z: An Essay (trans. Richard Miller), New York: Hill and Wang.

(1967)'The Death of The Author' in (1977), Image, Music, Text, London: Fontana, pp.

142-148.

__ (1980), Camera Lucida, London: Verso.

Benjamin, W. ([1934] 1995), Illuminations, London: Verso.

Berger, G. (2006), The History of Crass, London: Cherry Red.

Bestley, R. and Ogg, A. (2012), The Art of Punk: Posters + Flyers + Fanzines + Record Sleeves, London: Omnibus Press.

Chang, R. (2013), ‘693 Copies of the Beatles', White Album, Brooklyn: New York: Dust and Grooves, dustandgrooves.com. Accessed 11 July 2015. 
Connell, M. (2012), 'Talking about old records: Generational musical identity among older people', Popular Music, 31:2, pp. 261-78.

Crass (1978), The Feeding of The Five Thousand, Small Wonder Records.

__ (1979a), Reality Asylum, United Kingdom: Crass Records (first card cover press).

(1979b), Reality Asylum, United Kingdom: Crass Records (newspaper sleeve second press).

(1979c), The Feeding of the Five Thousand: The Second Sitting, United Kingdom:

Crass Records.

(1979d), Stations of the Crass, United Kingdom: Crass Records.

(1980), Reality Asylum, United Kingdom: Crass Records ([est] quality paper third press).

(1981a), Reality Asylum, Tokyo: Japan Records Inc. (Japanese licensed pressing from United Kingdom, Rough Trade Records).

(1981b), United Kingdom: Big A Little a/Nagasaki Nightmare, Crass Records.

_ (1982a), Sheep Farming in the Falklands, United Kingdom: Crass Records.

(1982b), How Does it Feel to be The Mother of a Thousand Dead?, United Kingdom:

Crass Records.

(1983), Reality Asylum, United Kingdom: Crass Records ([est] quality paper fifth press).

(1984a), 'You're Already Dead', United Kingdom: Crass Records.

(1984b), Best Before, United Kingdom: Crass Records.

Crass/Poison Girls (1980), Bloody Revolutions, United Kingdom: Crass Records. 
Debord, G. (1967), La Société Du Spectacle, Paris: Buchet-Chastel.

De Certeau, M. (1984), The Practice of Everyday Life, Berkeley: University of California Press.

Deleuze, G. (1980), A Thousand Plateaus, Paris: Les Editions de Minuit.

Del Pilar Blanco, M. and Peeren, E. (eds) (2013), The Spectralities Reader: Ghosts and Haunting in Contemporary Cultural Theory, London: Bloomsbury Academic.

Derrida, J. (1994), Spectres of Marx: The State of the Debt, the Work of Mourning and the New International, London: Routledge.

Fiske, J. (1990a), Reading the Popular, London: Routledge.

_ (1990b), Understanding Popular Culture, London: Routledge.

(1992), 'The cultural economy of fandom', in L. Lewis (ed.), The Adoring Audience, London: Routledge, pp. 30-49.

Gordon, A. F. (2008), Ghostly Matters: Haunting and the Sociological Imagination, Minneapolis: University of Minnesota Press.

Gramsci, A. (1986), Selections from Prison Notebooks, London: Lawrence and Wishart. 
Guedes-Bailey, O., Cammaerts, B. and Carpentier, N. (2008), Understanding Alternative Media, London: McGraw Hill.

Hall, S. (1973) 'Encoding and Decoding in the Media Discourse', Stencilled paper 7, pp. 120.

(1980), 'Encoding/decoding', in S. Hall et al. (eds), Culture, Media, Language: Working Papers in Cultural Studies, 1972-79, London: Hutchinson, pp. 15-47.

Hebdidge, D. (1979) Subculture: The Meaning of Style, London Routledge.

Jenkins, H. (1992), Textual Poachers, London: Routledge.

King, D. (2013), Secret Origins of the Crass Symbol, Oakland: \& Pens Press.

Lull, J. (1995), Media, Communication, Culture: A Global Approach, London: Polity Press.

Marx, K. (1975), Marx: Early Writings, London: Penguin.

McKay, G. (1996), Senseless Acts of Beauty: Cultures of Resistance since the Sixties, London: Verso.

(ed.) (1998), DiY Culture: Part \& Protest in Nineties Britain, London: Verso.

Morley, D. and Brunsdon, C. (1978), Everyday Television - Nationwide, London: BFI. (1980), The Nationwide Audience: Structure and Decoding, London: BFI. 
__(1986) Family Television: Cultural Power and Domestic Leisure, London: Routledge. (1992), Television, Audiences and Cultural Studies, London: Routledge.

O’Connor, A. (2008), Punk Record Labels and the Struggle for Autonomy: The Emergence of $D I Y$, Toronto: Lexington Books.

Rimbaud, P. (2014), Shibboleth: 'A Bit of' My Revolting Life, London: Exitstencil Press.

Rojek, C. (1995) , Decentring Leisure: Rethinking Leisure Theory, London: Sage.

Rudi (1978), I Spy, United Kingdom: Good Vibrations Records.

Shuker, R. (2010), Wax Trash and Vinyl Treasures: Record Collecting as a Social Practice, Surrey: Ashgate.

Stiff Little Fingers, Inflammable Material, United Kingdom: Rough Trade Records.

The Anti Nowhere League (1981), Streets of London b/w So What, United Kingdom: WXYZ Records.

The Beatles (1968), The White Album, United Kingdom: Apple Records.

The Clash (1978), The Cost of Living e.p., North America: CBS Records. (1980a), London Calling, North America: CBS Records. (1980b), Sandinista, North America CBS Records.

The Desperate Bicycles New Cross (1978), New Cross, United Kingdom: Refill Records. The Flys (1979), Waikiki Beach Refugees, United Kingdom: EMI Records. 
The Sex Pistols (1977), Never Mind The Bollocks, United Kingdom: Virgin Records.

The Stranglers (1980), Who Wants the World, United States: United Artist Records.

Thornton, S. (1995), Club Cultures: Music, Media and Subcultural Capital, London: Polity.

UK Subs (1979), Another Kind of Blues, United Kingdom: Gem Records.

Various (1978a), Battle of the Bands e.p., United Kingdom: Good Vibrations Records. (1978b), Live Stiffs, United Kingdom: Stiff Records.

Vaucher, G. (1999), Crass Art and Other Pre Post-Modernist Monsters, Edinburgh/London: AK Press/Exitstencil Press.

Wreckless Eric (1978), Wreckless Eric, United Kingdom: Stiff Records.

\section{Contributor details}

Alastair 'Gords' Gordon is Senior Lecturer in Media and Communications at Leicester De Montfort University. His current research is based around genre authenticity and hierarchy across international networks of DiY punk with specific focus on Japan and Europe. He researches in and runs modules on paranormal media and esoteric cultures. In 2012, Gords co-founded the Punk Scholars Network with Mike Dines and records and tours internationally with his band, Endless Grinning Skulls. Gords hates Tories and neo-liberals and collects platform shoes.

Contact:

Leicester Media School, De Montfort University, The Gateway, Leicester LE1 9BH, United Kingdom. 
E-mail: agordon@dmu.ac.uk

Notes

${ }^{1}$ I have to confess, the first time I played the track I scratched the record on the side of the turntable and chucked it in the front-room bin. I still have mixed feelings about this, although I waited another week and got another copy. Thankfully, I still own this one.

${ }^{2}$ McKay's claim is not strictly accurate. The maximum price ('70p Maximum Retail Price') was included on just one Desperate Bicycles record - their third release, the New Cross, New Cross EP, in February/March 1978 - while other examples of similar low-pricing strategies can be seen in a range of punk and New Wave releases between 1977 and 1979 with prices printed directly on the covers. These came from both emerging independent and punk-oriented labels: Alberto Y Lost Trios Paranoias ‘Heads Down, No Nonsense, Mindless Boogie' double pack, Logo Records, August 1978 ('Two for the Price of One, 75p RRP'); the Battle of the Bands EP, December 1978 ('2-Single Pack f1.49 RRP); and Rudi I Spy EP, November 1979 ('99p') on the Good Vibrations label. Moreover, several Stiff Records releases including the compilation Live Stiffs (only $£ 2.99$ RRP) and the eponymous debut album by Wreckless Eric (bizarrely priced at 'only 69/11d'). Major labels were equally involved with this practice employing loss-leaders to promote their acts, such as the Flys' Waikiki Beach Refugees, EMI Records, October 1978 ('a 45 r.p.m. for 45p') and The Stranglers' Who Wants the World, United Artists, May 1980 ('79p RRP'). The Clash were noted for their attempts to give 'value for money with record releases, including the Cost of Living EP, CBS May 1978; the 'double for the price of a single album' London Calling (The Clash 1980a) and follow-up triple-album Sandinista (The Clash 1980b). Other bands such as 
Stiff Little Fingers followed suit, although it could be argued that by this time the precedent of Crass Records' success with the strategy had led the major labels to seek to imitate it, though with more of a marketing than an ideological imperative.

${ }^{3}$ This record also contained previous examples of the Dave King Crass logo, although clearly not in the stark from cover detail of Reality Asylum.

${ }^{4}$ The only other Crass vinyl release in Japan was the Rough Trade licensed version of the 1981 Penis Envy LP.

${ }^{5}$ Aside from my copies of the five, respective original pressings, these will be retained in my personal collection. 